\title{
The Surgical Approach to Short Bowel Syndrome - Autologous Reconstruction versus Transplantation
}

\author{
Aparna Rege \\ Division of Transplantation, Department of Surgery, Duke University Medical Center, Durham, NC, USA
}

\section{Keywords}

Short bowel syndrome - SBS - Parenteral nutrition .

$\mathrm{PN} \cdot$ Autologous gastrointestinal reconstruction .

AGIR · Longitudinal intestinal lengthening and tailoring ·

LILT · Serial transverse enteroplasty · STEP .

Ultra-short bowel syndrome · USBS

\section{Summary}

Background: Short bowel syndrome (SBS) is a state of malabsorption resulting from massive small bowel resection leading to parenteral nutrition (PN) dependency. Considerable advances have been achieved in the medical and surgical management of SBS over the last few decades. Methods: This review discusses in detail the surgical approach to SBS. Results: Widespread use of PN enables long-term survival in patients with intestinal failure but at the cost of PN-associated lifethreatening complications including catheter-associated blood stream infection, venous thrombosis, and liver disease. The goal of management of intestinal failure due to SBS is to enable enteral autonomy and wean PN by means of a multidisciplinary approach. Availability of modified enteral feeding formulas have simplified nutrition supplementation in SBS patients. Similarly, advances in the medical field have made medications like growth hormone and glucagon-like peptide (GLP2) available to improve water and nutrient absorption as well as to enable achieving enteral autonomy. Autologous gastrointestinal reconstruction (AGIR) includes various techniques which manipulate the bowel surgically to facilitate the bowel adaptation process and restoration of enteral nutrition. Ultimately, intestinal transplantation can serve as the last option for the cure of intestinal failure when selectively applied. Conclusion: SBS continues to be a challenging medical problem. Best patient outcomes can be achieved through an individualized plan, using various AGIR techniques to complement each other, and intestinal transplantation as a last resort for cure. Maximum benefit and improved outcomes can be achieved by caring for SBS patients at highly specialized intestinal rehabilitation centers.

\author{
Schlüsselwörter \\ Kurzdarmsyndrom · KDS · Parenterale Ernährung · \\ PE · Autologe gastrointestinale Rekonstruktion . \\ AGIR · Longitudinale intestinale Verlängerungsoperation . \\ LILT · Serielle transverse Enteroplastie - STEP . \\ Ultrakurzdarmsyndrom · USBS
}

\section{Zusammenfassung}

Hintergrund: Das Kurzdarmsyndrom (KDS) stellt einen Zustand der Malabsorption dar, der aus einer massiven Dünndarmresektion, die zur Abhängigkeit von parenteraler Ernährung (PE) führt, resultiert. In den letzten Jahrzehnten wurden erhebliche Fortschritte in der internistischen und chirurgischen Behandlung des KDS erreicht. Methoden: Diese Übersicht beschreibt im Detail die chirurgische Herangehensweise an das KDS. Ergebnisse: Die weit verbreitete Verwendung von PE ermöglicht ein Langzeitüberleben bei Patienten mit Darmversagen, jedoch auf Kosten der PE-assoziierten lebensbedrohlichen Komplikationen wie Katheter-assoziierter Blutvergiftung, Venenthrombose und Lebererkrankung. Das Ziel des Managements von Darmversagen aufgrund von KDS ist die Ermöglichung einer enteralen Autonomie und die Entwöhnung von der PE durch einen multidisziplinären Ansatz. Die Verfügbarkeit von modifizierten enteralen Ernährungsformen hat die ergänzende Nährstoffversorgung von KDS-Patienten vereinfacht. Gleichzeitig haben Fortschritte in der Medizin dafür gesorgt, dass das Wachstumshormon und Glucagon-like-Peptide (GLP2) zur medikamentösen Behandlung zur Verfügung stehen, um die Wasser- und Nährstoffabsorption zu verbessern und das Erreichen einer enteralen Autonomie zu ermöglichen. Die autologe gastrointestinale Rekonstruktion (AGIR) umfasst verschiedene Techniken, die den Darm chirurgisch manipulieren, um den Anpassungsprozess des Darms und die Wiederherstellung der enteralen Ernährung zu erleichtern. Letztlich kann eine Darmtransplantation als letzte Option zur Heilung von Darmversagen dienen, wenn diese selektiv angewendet wird. Schlussfolgerung: Das KDS stellt weiterhin eine schwierige medizinische Herausforderung dar. Die besten Ergebnisse für die Patienten können mittels einer individuellen Planung, in deren Rahmen sich verschiedene AGIR-Techniken ergänzen, sowie der Darmtransplantation als letzte Möglichkeit der Heilung erreicht werden. Maximaler Nutzen und verbesserte Ergebnisse können durch die Betreuung von Patienten mit KDS in hochspezialisierten Darmzentren erreicht werden.

\begin{tabular}{ll}
\hline KARGER & (c) 2014 S. Karger GmbH, Freiburg \\
1662-6664/14/0303-0179\$39.50/0 \\
$\begin{array}{l}\text { Fax+49 761 4520714 } \\
\text { Information@Karger.com } \\
\text { www.karger.com }\end{array}$ & $\begin{array}{l}\text { Accessible online at: } \\
\text { www.karger.com/vim }\end{array}$
\end{tabular}




\section{Introduction}

Since its introduction in the late 1960's, parenteral nutrition $(\mathrm{PN})$ has been the mainstay of therapy for patients with intestinal failure [1]. Advances in recent years have improved survival in PN-dependent patients, primarily through a multidisciplinary approach including various medical and surgical rehabilitation strategies aimed at achieving enteral autonomy [2-4]. Yet, 19-26\% of patients continue to be permanently PN-dependent and develop a high rate of complications that lead to high mortality rates of $13-38 \%$ by $2-5$ years following the development of intestinal failure $[5,6]$.

This review aims at discussing the various strategies involved in the surgical approach to short bowel syndrome (SBS).

\section{Surgical Rehabilitation in Intestinal Failure}

Initial surgical management of patients at risk for SBS includes every attempt to conserve as much bowel as possible even though planned serial 'second look' surgeries may be required to evaluate for viability of marginal bowel segments. Following recovery from the initial episode and return of bowel function, administration of enteral feeds and, if possible, early stoma closure are recommended to enhance adaptation and help in weaning PN [7]. In almost $75 \%$ of patients with SBS, intestinal adaptation precludes the need for surgical rehabilitation and is often sufficient to support growth and long-term survival [8]. However, since adaptation is a slow process extending over 6 months to 2 years, patients should be given adequate time to reach their full adaptive potential prior to any surgical consideration $[8,9]$.

Bowel adaptation is a remodeling process, involving compensatory mechanisms aimed at improving the absorptive capacity of the remnant bowel following intestinal loss. Increase in the intestinal mass and surface area occurs through enterocyte and crypt cell proliferation, increase in microvilli with taller villi and deeper crypts, and hyperplasia and hypertrophy of the smooth muscle layers. Adaptation is an ongoing process that begins $24-48 \mathrm{~h}$ after surgical resection, progressing rapidly during the initial 4-24 months following intestinal loss, and can take years to complete $[10,11]$. Following intestinal resection the motor activity of the bowel is also disrupted for a few months [12]. Studies have demonstrated a shorter duration of migrating motor complex cycle and fed pattern after resection [13]. Once this initial phase is over, motor adaptation begins, more prominently in the jejunum than in the ileum. Combination of the structural and motor adaptation results in prolonged intestinal transit time and improved absorption by individual enterocytes.

Various factors influencing intestinal adaptation include gastrointestinal regulatory peptides, growth factors, hormones, and cytokines in addition to tissue factors including immunity, blood flow, and neural influences $[14,15]$. The ex- tent of resection also strongly influences the degree of intestinal adaptation and thereby the ability to wean PN [16]. Although the ileum has a greater adaptive capacity than the jejunum, massive ileal resection has a significantly worse impact than jejunal resection, as the ileum plays an important role in electrolyte and water absorption as well as absorption of vitamin $B_{12}$, bile salts, and fatty acids $[17,18]$. Younger patients (infants and neonates) are much more likely to adapt due to periods of rapid bowel growth as evidenced by nearly a doubling of the bowel length in the first 18 months of life, and hence they are more likely to wean off PN $[19,20]$.

In some patients, however, rapid bowel growth results in excessive dilatation of the remnant bowel resulting in dysmotility and stasis which promotes bacterial overgrowth contributing to malabsorption, bacterial translocation with systemic infection, and ultimately liver injury [21, 22]. This may further negatively impact ongoing adaptation and thus the ability to wean PN [23, 24]. Since bowel dilatation is a natural sequel of adaptation, surgery should be deferred unless dilatation causes recurrent episodes of bacteremia $[25,26]$. It is noted that bowel dilatation occurs more commonly in younger patients who more often are candidates for surgical rehabilitation as compared to adults [27].

\section{Autologous Gastrointestinal Reconstruction}

Most centers are conservative in recommending intestinallengthening procedures, only offering it as an adjunct to nutritional and medical management in patients who have reached a plateau in weaning PN. When allowing spontaneous intestinal adaptation, frequent assessment is needed to reassure adequate growth while avoiding intestinal failure-associated liver disease (IFALD) and other serious complications of PN such as recurrent line infections and loss of venous access [28, 29].

Due to the PN-associated comorbidities, the initial goal in management of patients with intestinal failure is to enable PN weaning. Autologous gastrointestinal reconstruction (AGIR) further facilitates the adaptation process and attempts to reverse complications of PN. AGIR can be considered once maximal adaptation is achieved and further weaning of PN fails or with recurrence of malabsorption in previously achieved partial or complete adaptation as demonstrated by stable fluid and/or calorie requirements from intravenous supplementation [30, 31]. With the onset of PN-induced advanced liver disease manifested by coagulopathy and portal hypertension, intestinal transplantation remains the only salvageable option $[32,33]$.

The principle of AGIR relies on bowel dilatation resulting from post-resectional adaptation [34] and the ability to manipulate this dilated bowel surgically to improve the dysmotility and the absorption, thereby facilitating enteral autonomy [35]. Of the various methods of reconstruction, tapering enteroplasty, Bianchi's longitudinal intestinal lengthening and tailoring (LILT), and the serial transverse enteroplasty (STEP) have gained wide acceptance [34]. The main predictor 


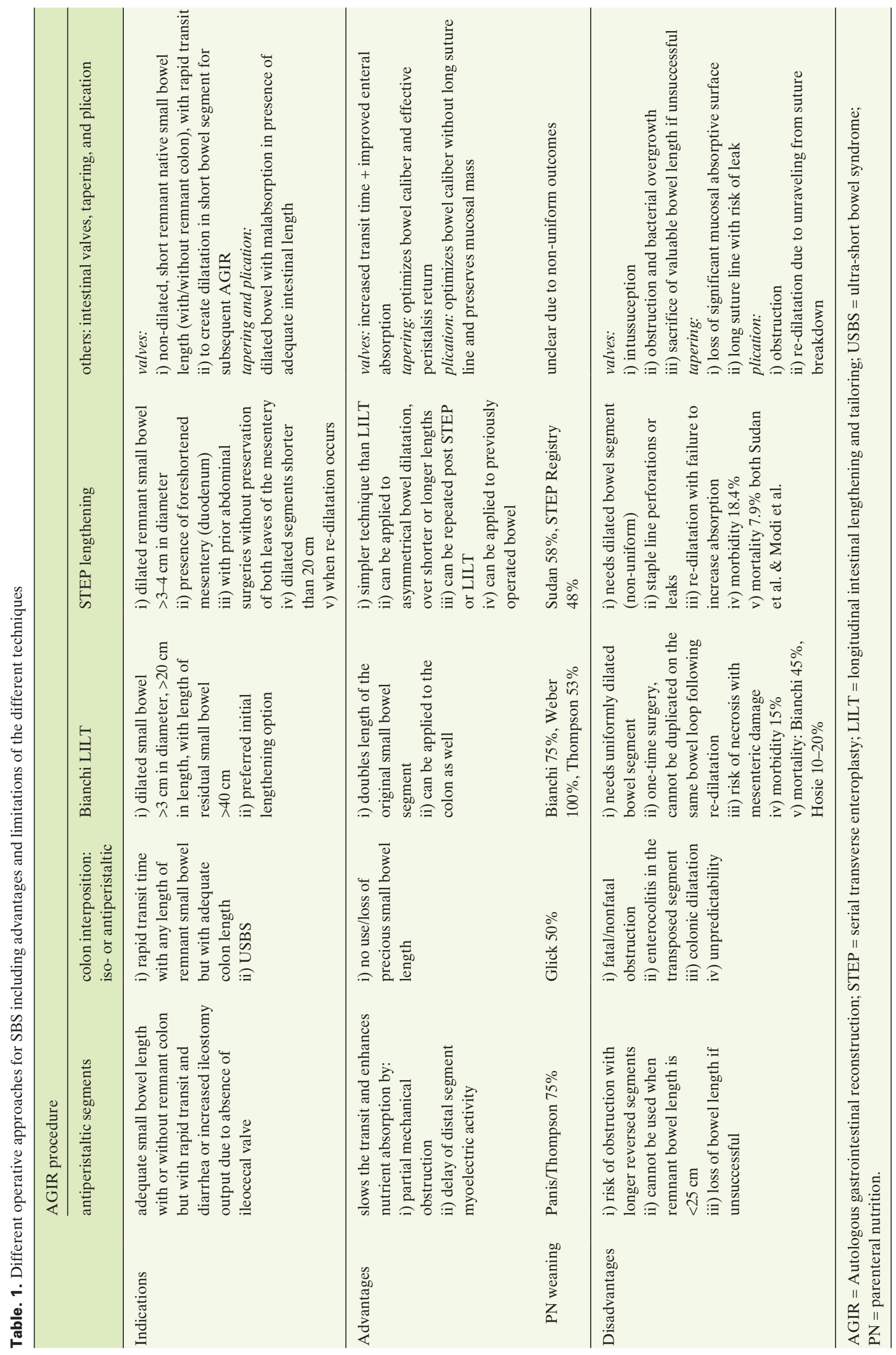


Fig. 1. Bianchi

LILT. A Separating the two leaves of the mesentery carrying blood supply to half of the circumference of the bowel. B Creating a mesenteric tunnel for division of the dilated bowel.

C, D Division of the dilated bowel with a surgical stapler into two separate pieces, one-half the size of the original dilated loop. E The two bowel loops are then anastomosed together in an isoperistaltic manner. (Reproduced with permission from [60].)

of the ability to achieve enteral autonomy following AGIR is the final length of the remaining small intestine [36, 37]. It is now well accepted that with a remnant bowel length $<40 \mathrm{~cm}$, the probability of permanent PN dependency is fairly high [38]. In such cases, where the chance of spontaneous adaptation is minimal, creating controlled obstruction to actively generate bowel dilatation is suggested in order to be able to perform AGIR surgery later [39].

Careful patient selection is essential to avoid unnecessary operations, since some infants especially with low birth weight and necrotizing enterocolitis as the etiology leading to a very short bowel remnant may wean off PN without any AGIR procedures at all [38].

In a select group of patients, despite long remnants of small bowel, rapid transit results in increased ileostomy output due to absence of ileocecal valve (ICV) and colon. Placing a reverse intestinal segment proximal to the ileostomy in such cases can suffice to slow the transit and facilitate nutrient and fluid absorption. These patients often wax and wane clinically, requiring nutrient and fluid replacements periodically [40]. This concept of reversed intestinal segment dates back to the 1880's [41]; however, it received more popularity in the latter half of the 20th century as one of the earliest surgical procedures designed to slow intestinal transit $[42,43]$.

An antiperistaltic bowel loop, by its virtue, creates partial mechanical obstruction and delays myoelectric activity in the distal segment, thus slowing the transit to enhance nutrient absorption [44].

Although smaller case series have suggested a length of the reversed segment between $10-15 \mathrm{~cm}$ for adults and around 3 $\mathrm{cm}$ for children for maximal benefit $[45,46]$, uncertainty in establishing the ideal length and location of the reversed intestinal segment produced variable results when applied clinically. Despite the purported benefits, this technique failed to gain popularity due to the potential risk of obstruction with longer
Fig. 2. STEP: Serial transverse application of a linear stapler, on alternate sides' midway between the mesenteric and anti-mesenteric border, creating a 'zig-zag' longer, narrower intestinal channel which straightens over a period of time. (Reproduced with permission from [132].)

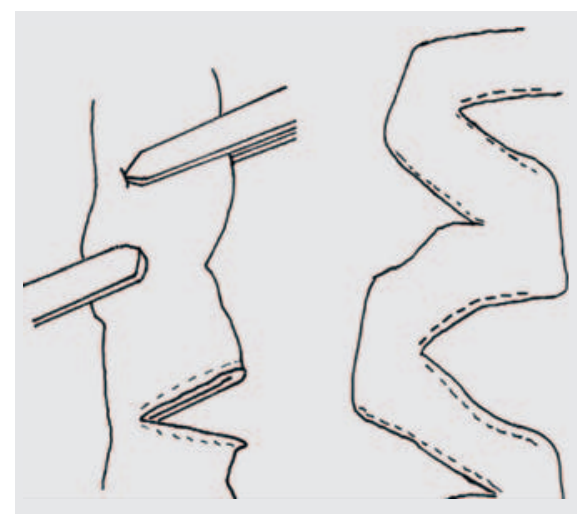

reversed segments [47]. Obviously, this technique cannot be used when the remnant bowel length is $<25 \mathrm{~cm}$.

A recent largest series of SBS patients treated with reversed segment concluded that a distally placed reversed intestinal segment of $10-12 \mathrm{~cm}$ is an appealing and safe conservative alternative to small bowel transplantation in adults with 'permanent' PN dependency, with a minimum small bowel length (SBL) of $25 \mathrm{~cm}$, and without chronic liver failure [48]. Unlike other procedures, it can be performed regardless of the bowel diameter with the expectation of almost half of the patients to be weaned from PN.

When remnant bowel represents $10 \%$ (with ICV) or $20 \%$ (without ICV) of predicted SBL, it is termed ultra-short bowel syndrome (USBS). It usually arises from massive small bowel resection, congenital jejuno-ileal atresia, or in rare cases of vanishing gastroschisis. In such cases AGIR should be considered as a complementary rather than a rescue procedure [49].

A recent small case series of patients with USBS due to jejunal atresia has shown that persistent proximal obstruction with sham feeds and periodic gastrostomy tube clamping helps to dilate the proximal jejunal remnant and optimizes the potential for AGIR [50]. Following lengthening procedure (STEP), the SBL increases by an average of nearly $300 \%$ in comparison to the average expected increase of $37 \%$ without therapy. Sham feeds and gastrostomy clamping alone produced a mean SBL increase of $159 \%$, suggesting that the technique can dramatically augment gut growth within the first few months of life compared to the rate of expected normal growth.

Different AGIR options (table 1) must be tailored individually according to the length and type of residual intestine, but in certain situations combination of various techniques may prove more beneficial than a single procedure. USBS is a perfect example of this situation. Enteral autonomy has been reported in a patient with a remnant of $5 \mathrm{~cm}$ of the jejunum and entire colon with definitive surgery aimed at lengthening the remnant jejunum and part of the colon (Bianchi technique), delaying transit with antiperistaltic anastomosis of the lengthened colon, and increasing the rectal capacity by creating a hypotonic reservoir proximal to the rectum with a sigmoid $\mathrm{J}$ pouch in order to diminish both urgency and frequency of stools [51]. This report indicated that similar to the small 
bowel, colonic duplication is also technically feasible. A beneficial delay in intestinal transit can be achieved with careful antiperistaltic colonic interposition, despite prior reports of unpredictability and fatal obstruction [52].

In the event of a too short remnant small bowel precluding AGIR, isoperistaltic colon interposition can be a useful technique in patients with USBS [53]. Under exceptional circumstances the colon adopts an important metabolic role, with bacterial metabolism and fermentation within the colon exerting a significant trophic effect on the mucosa of the small intestine and colon [54]. The colonic segment adapts to its new location with hypertrophy and hyperplasia of the mucosal crypt glands and developing contractile responses similar to those of the remaining small bowel $[55,56]$. However, complications arising from colonic dilatation and enterocolitis within the transposed segment make this procedure rather unappealing.

One of the simpler procedures of AGIR is a tapering enteroplasty, which involves excising a wedge of the antimesenteric border of the dilated bowel followed by suturing the remnant bowel into a tube [57]. This reduces the diameter of the dilated bowel and facilitates an early return of effective peristalsis. This procedure was preferred to resection for managing dilated bowel in jejunal atresia [58]. Since tapering enteroplasty optimizes bowel caliber at the expense of loss of significant mucosal absorptive surface, it should be reserved to tackle stasis and malabsorption in a dilated bowel only in the presence of adequate intestinal length. It can also be a procedure of choice when vascular anatomy of the dilated bowel does not permit bowel division for a lengthening procedure. Tapering results in a long suture line that may increase the risk of anastomotic leakage.

The technique of intestinal plication was designed by circumferential plication of the dilated bowel after folding the redundant antimesenteric wall into the lumen to avoid the long anastomotic suture line of enteroplasty and also preserve the mucosal mass which is an important consideration in SBS [59]. With long-term follow-up, development of obstruction and redilatation due to unraveling from suture breakdown has been reported.

One of the biggest revolutions in the management of SBS came about in 1980, when Bianchi reported the longitudinal intestinal lengthening procedure which doubled the length of the original segment (fig. 1) [60]. Anatomic variations of the blood supply, such as predominant blood supply to one side of the intestinal wall, limit the potential success of the procedure [61]. Hence, an account of the vascular pattern should always be taken into consideration before splitting the mesentery and transecting the bowel. Various modifications of the Bianchi procedure include using cautery and sutures to minimize stapler-associated leaks and bleeding [62] and oblique stapler application at the proximal and distal ends of the dilated small bowel to obviate the need for complete bowel division, creating a single hand-sewn anastomosis and thus eliminating potential sites of leak or stricture with two anastomoses [63].
Anatomic criteria suggested for patient selection for LILT include i) intestinal diameter $>3 \mathrm{~cm}$, ii) length of residual small bowel $>40 \mathrm{~cm}$, and iii) length of dilated bowel $>20 \mathrm{~cm} \mathrm{[64].}$

However, others suggest that regardless of the bowel length, intestinal lengthening procedures are indicated with life-threatening complications of $\mathrm{PN}$ or when substantial bowel dilatation occurs with intestinal failure [65].

In the event the bowel mesentery is unavailable for splitting due to adhesions from previous surgeries or when the short gut consists of only the dilated duodenum, the Iowa two-step elongation procedure, another modification, seems more appropriate than LILT [66]. Here, the bowel is initially connected to a host organ, such as liver [66], abdominal wall [67], or adjacent bowel [68], to allow vessel collaterals to grow into the attached bowel segment, following which the bowel is lengthened with a longitudinal split followed by isoperistaltic anastomosis of the resulting new bowel loops. Since this method requires multiple laparotomies with several weeks of time between surgeries to enable parasitization of the blood supply, it failed to find widespread application.

A review of worldwide published series of LILT revealed varying results with an overall survival ranging from 30 to $100 \%$, and the ability to wean from PN as $28-100 \%[35,69-$ 71]. Early reports of the LILT showed a high complication rate with anastomotic stenosis, staple line leakage, interloop abscess and fistulae formation, and hemiloop necrosis resulting from vascular compromise [35, 72], but with more experience the complication rate has been reduced [70]. LILT is a technically difficult procedure with disadvantages including the necessity for uniform dilatation of the segment to be lengthened and occurrence of recurrent dilatation necessitating additional surgeries. This procedure is a one-time surgery which cannot be repeated on the same intestinal segment, as the vasculature within the mesentery is not further dissectable; however, LILT is definitely feasible after a prior STEP [73].

In 2003, STEP, a simpler technique of bowel lengthening, was introduced by Kim to limit dilatation with minimal risk of intestinal ischemia and in the absence of uniform dilatation over a longer segment (fig. 2) [74]. STEP was first clinically applied to dilated bowel following a Bianchi LILT [75]. From the technical perspective STEP has many clear advantages over LILT as it is easily reproducible, precludes the need of an anastomosis, requires minimal mesenteric dissection, reducing the chance of vascular compromises, and above all it can be performed primarily or repeatedly in patients who develop redilation of their bowel after a LILT or STEP procedure [76, 77]. Asymmetrical bowel dilatations in the short bowel consisting of intricate intestinal segments such as the duodenum and adjacent jejunum are better served with STEP than LILT [74]. STEP has also shown promising results as a primary procedure in neonates with intestinal atresia and marginal length $[78,79]$. Problematic bacterial overgrowth including D-lactic acidosis has been better handled with a STEP procedure since, besides reducing stasis and increasing carbo- 
hydrate and fat absorption, it decreases the overall bacterial load, thus reducing the amount of carbohydrate substrate available for D-lactic acid production [80].

Adaptation continues after STEP procedure, requiring on average 1-2 years for noticing significant improvement in intestinal absorption and function. The progress can be gauged by studying various markers like D-xylose [81], a marker of carbohydrate absorption and mucosal integrity, plasma citrulline [82], a marker of small bowel enterocyte mass, and fecal fat content, a marker of intestinal absorptive function. Improvement in intestinal function is secondary to an absolute increase in mucosal absorptive surface area or healing of existing inflamed and atrophic mucosa resulting from stasis and bacterial overgrowth. Intestinal bacterial load also decreases post-STEP, and gradually, with an absolute increase in the surface area, the residual intestine begins to dilate, representing ongoing intestinal adaptation. It takes an average of about 12-24 months for redilatation [83].

However, excessive dilatation may re-invite stasis and bacterial overgrowth resulting in malabsorption, and this prevents achievement of intestinal autonomy in a significant proportion of patients. This is when a repeat STEP or surgical tapering is required [84]. Following a repeat STEP, $13-43 \%$ of patients successfully wean off PN regardless of type of initial bowel lengthening [85]. Principles to be followed during repeat STEP include firing of the stapler twice in an alternating fashion between each initial staple line to maintain the intestinal continuity, avoiding the creation of blind ends of bowel, or the other option involves single stapler application between each initial staple line resulting in several blind ends that ultimately need resection [86]. To ensure good blood supply, the staple firings should be applied in a sufficiently dilated segment of bowel which may be difficult due to the asymmetric bowel dilatation after the primary STEP [87].

In order to better track STEP outcomes worldwide, a webbased International Data Registry for patients undergoing STEP was established at www.stepoperation.org.

The choice for one of both surgical lengthening options is essentially driven by feasibility of the procedures and the associated outcome. A Bianchi is the preferred initial surgical option for lengthening, enabling a STEP to be performed at a later date once recurrent dilation occurs. Similarly, the STEP procedure is the better choice when patients have foreshortened mesentery or prior surgeries without preservation of both leaves of the mesentery $[74,88]$. Since higher failure and mortality rates have been reported with LILT in shorter remnant intestinal segments, STEP should be the indicated lengthening procedure for dilated segments shorter than $20 \mathrm{~cm}$ [89].

Both LILT and STEP are comparable procedures without any obvious advantages over each other. The rate of total PN weaning is more or less similar in both but STEP enables rapid wean of total $\mathrm{PN}$ due to its ability to increase the final length to more than $100 \%$ of the original length in contrast to Bianchi LILT, where the original length is only doubled [88].
Earlier procedures designed to delay intestinal transit included artificial valves, recycling loops and pouches, and intestinal pacing [35]. Outcomes with these procedures have not been uniformly successful and as such they are only of historical significance. Interestingly, intussusception valve, created by the eversion technique similar to creating an ileostomy, found a role in dilating short segments of bowel by partial mechanical obstruction, subsequently allowing intestinal lengthening procedures [90]. However, since valuable small bowel length is sacrificed in valve construction and subsequent uncontrollable bowel obstruction may demand valve removal, the procedure failed to gain popularity [35].

All available literature suggests that no single AGIR technique offers a rapid guaranteed cure for intestinal failure without any potential complications. Attempts to achieve enteral autonomy are generally better with longer bowel lengths and a greater initial absorptive capability [88]. End-stage liver failure is a clear contraindication for AGIR and necessitates transplantation; hence, bowel lengthening procedures should be performed before the development of liver disease in SBS patients [91]. The role of surgical rehabilitation is to obviate the need for intestinal transplantation but when it fails to generate adequate bowel length for a healthy, disease-free survival, AGIR serves as a bridge to intestinal transplantation [92].

\section{Intestinal Transplantation}

Over the years, small bowel transplantation has emerged as a curative alternative in patients with intestinal failure enabling reduction in $\mathrm{PN}$-associated complications and providing an improved quality of life with better nutrition. The main goal of intestinal transplantation is the restoration of enteral nutrition. Up to $90 \%$ of patients undergoing intestinal transplantation can be free of PN [32].

Following the initial pioneering work by Alexis Carrell in the 20th century and animal experiments by Lillehei in 1959 [93], the first clinical transplants were performed in pediatric patients in Boston in 1964 [94]. The initial attempts failed due to technical complications and lack of effective immunosuppressive regimens $[95,96]$. The first successful multivisceral transplantation with survival was reported by Thomas Starzl et al. [97] in 1987, followed by Goulet et al. [98] reporting the first successful isolated small bowel transplant with long-term survival, and Grant et al. [99] reporting the first combined transplantation of liver and small bowel in 1989.

Further remarkable improvements in patient and graft survival have been attributed to technical improvements, novel immunosuppressive agents, better understanding of the immune and gastrointestinal physiology, significant advances in anesthesia and critical care, and an overall increase in clinical program experience [100-102].

The major revolution in intestinal transplantation came when the Center for Medicare and Medicaid Services (CMS) 
Fig. 3. Isolated intestinal transplantation: The entire jejunum and ileum is transplanted with or without the colon maintaining as much functional native bowel as possible. The arterial inflow is through an anastomosis between the graft superior mesenteric artery and the native aorta whereas the venous drainage is established into the inferior vena cava or the mesenteric portal sys-

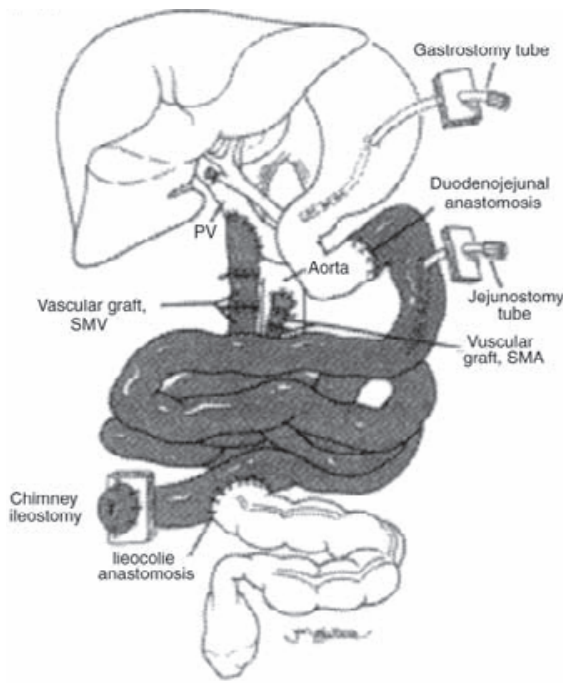

tem (as shown) through the graft superior mesenteric vein (transplanted organs are shaded). (Reproduced with permission from [32].)

accepted bowel transplant as the standard of care for intestinal failure patients failing PN and other medical or surgical rehabilitation attempts, and offered insurance coverage for the procedure [103].

Currently, small bowel transplantation is offered to SBS individuals who experience PN failure including recurrent catheter-related infections (more than two per year, fungemia, shock, acute respiratory distress syndrome (ARDS)), thrombosis of two of the six major central venous accesses, alterations of growth and development in children, severe dehydration with refractory electrolyte changes, and impending liver failure or established liver disease with cirrhosis and portal hypertension [104]. Further indications also include treatment of motility disorders like total intestinal aganglionosis and microvillus inclusion disease, gastrointestinal neoplastic syndromes involving the celiac or mesenteric roots like desmoid tumors and well differentiated neuroendocrine tumors, and enterocyte deficiencies such as USBS with residual small intestine $<10 \mathrm{~cm}$ in infants and $<20 \mathrm{~cm}$ in adults $[105,106]$. When SBS results from certain abdominal catastrophes like extensive abdominal trauma, extensive intestinal resection, multiple enterocutaneous fistulas, or chronic diffuse mesenteric vascular thrombosis, complete replacement of all organs of the abdominal cavity (multivisceral transplantation (MVTx)) is required to reestablish normal physiology [107]. Multivisceral transplantation is also indicated with complex portal mesenteric system thrombosis [108], even in the absence of liver or intestinal failure, but more commonly in the context of liver transplantation with complete portal vein thrombosis extending into the superior mesenteric vein (grade III/IV per Yerdel classification) [109].

There is now an emerging philosophy of earlier intervention, with encouraging results reported in transplants being performed at an earlier stage [110] justified by the higher mortality faced by IFALD patients awaiting combined liver/ intestinal transplantation [111].
Intestinal transplantation has several variants depending on concomitant other organ failure needing replacement simultaneously with the intestines. Isolated intestinal transplantation (SBTx) is indicated in irreversible intestinal failure in the absence of associated severe liver dysfunction as proven by a liver biopsy (fig. 3). The graft may come from a cadaveric or a living donor. Perfect size match or size reduction, to transplant a segment of $200 \mathrm{~cm}$, is required to enable abdomen closure [112]. The combined liver-intestinal transplantation (SB-LTx) is indicated when intestinal failure patients have coexisting irreversible liver disease. Here, the liver can be transplanted separately or in continuity with the bowel, en bloc with the pancreaticoduodenal arc, via the Omaha technique in which biliary reconstruction is avoided as the donor duodenum serves as a conduit for biliary and pancreatic secretions from the graft (fig. 4). MVTx involves removal and replacement of both native foregut and midgut. The graft may include liver, kidneys, and large intestine depending on the need (fig. 5). In all these transplants, enterostomy of the distal graft ileum is performed to serve for graft surveillance through repeated biopsies assessing allograft rejection.

Intestinal rehabilitation plays an important role in adaptation post transplantation since grafts may have varying degrees of failure resulting in compromised tolerance to enteral feeding due to anatomical and functional changes induced by ischemia-reperfusion injury, denervation, absence of lymphatic drainage of the allograft, and rejection episodes [113, 114]. Initial nutrition is provided through PN with gradual transition to enteral diet comprising elemental or polymeric formulas when the graft shows signs of function [115]. A lowfat or low-long-chain triglyceride diet is sometimes preferred to reduce the risk of chylous ascites [116].

In children, a SB-LTx is the leading type of transplantation $(50 \%)$, followed by the isolated SBTx $(37 \%)$ and the MVTx $(13 \%)$. In adults, transplantation of the intestine alone is usually performed (55\%), followed by the MVTx (24\%) and the SB-LTx combination (21\%) [32]. Isolated SBTx is increasing in frequency and now exceeds the number of combined liver and intestine transplants which used to be performed more commonly [117]. Recent data from the international Intestinal Transplant Registry (ITR) and Scientific Registry of Transplant Recipients (SRTR) annual report have documented significant improvement in the patient and graft survival following intestinal transplantation in the last decade $[118,119]$.

For patients undergoing intestinal transplant in 2007, 1and 5-year graft survival was 69.2 and $53.8 \%$, respectively, for recipients $<18$ years, and 74.2 and $48.3 \%$, respectively, for recipients $>18$ years or older. 1- and 5-year graft survival was 74.6 and $48.0 \%$, respectively, among SBTx recipients, and 68.6 and $53.7 \%$, respectively, among SB-LTx recipients. Considering both recipient age and organ transplanted, adult recipients of intestinal transplants have the best 1-year graft survival $(79.6 \%)$, and pediatric recipients of intestine-liver transplants have the best 5-year graft survival (56.3\%) [117]. A 
Fig. 4. Combined liver-intestinal transplantation: The liver is transplanted en bloc with the small bowel, arterial supply is established through the superior mesenteric artery and celiac trunk graft through a conduit to the aorta, and venous drainage is made through the hepatic veins to the inferior vena cava. The venous drainage of the native viscera is established through a native portocaval shunt. The upper gastrointestinal continuity is maintained through the native stomach and pancreaticoduodenal complex which are retained and anastomosed to the transplant jejunum (transplanted organs are shaded). (Reproduced with permission from [32].)

significant decline in graft survival over the long term results from infections, malignancy, and chronic rejection [120].

Controversies regarding the inclusion of the colon due to the risk of infection have been challenged with recent reports from few single center series documenting benefits of continence and reduced incidence of dehydration with increased water absorption [121, 122]. Similarly, immunologic benefits, with inclusion of the spleen, in the pediatric population have been documented without altering the incidence of graft versus host disease [123]. Innovative techniques to deal with lack of space and difficult abdominal closure when loss of domain exists include transplantation of full-thickness abdominal wall [124] or vascularized [125] or non-vascularized rectus fascia [126] along with the intestinal allograft, reconstruction of the abdominal wall with acellular dermal matrix [127], and staged abdominal wall closure [128].

In some cases where there has been rapid progression of liver disease with preserved venous access and intestinal autonomy is possible, replacing the liver alone has been beneficial. Certain criteria were proposed by Dell-Olio et al. [129] for the success of isolated liver transplant (iLTx) in patients with intestinal failure which include i) established IFALD (serum bilirubin $>200 \mathrm{mmol} / \mathrm{l}$, moderate/severe fibrosis, portal hypertension), ii) at least $50 \mathrm{~cm}$ of remnant functional small bowel in the absence of ICV or $30 \mathrm{~cm}$ with ICV, iii) enteral tolerance of at least $50 \%$ of the estimated daily energy requirement with an associated increase in weight for a few weeks before the development of IFALD, and iv) no history of recurrent line infections in the presence of dilated dysmotile bowel. Increased organ availability from a cadaveric split liver or a living donor makes this option very attractive. Advantages include cure of
Fig. 5. Multivisceral transplantation: The native abdominal viscera is resected and the composite graft, including the liver, stomach, pancreaticoduodenal complex, and small intestine, are transplanted en bloc. The arterial supply is established through the superior mesenteric artery and celiac trunk graft through a conduit to the aorta and venous drainage through the hepatic veins to the inferior vena cava, when the liver is included (as shown) and through the graft por-

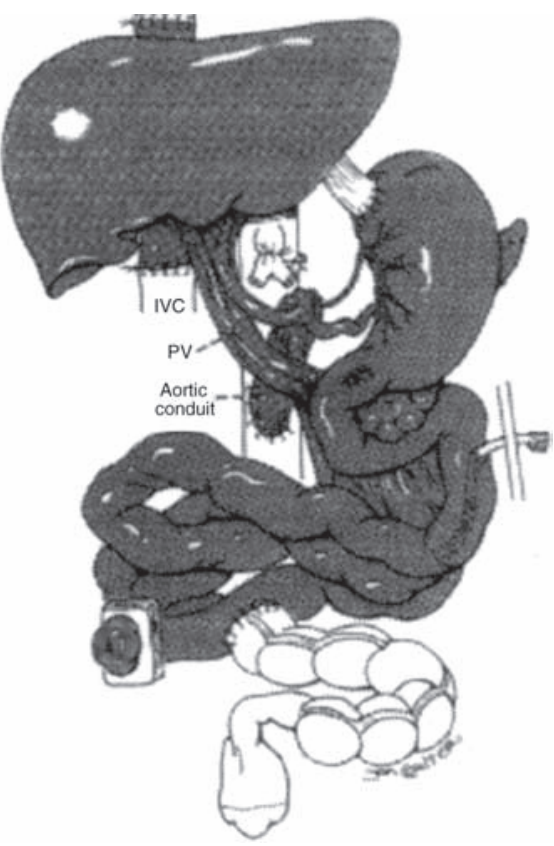
tal vein to the cava

when recipient liver is retained. The gut continuity is restored by anastomosing the esophagus or gastric remnant with the stomach graft (transplanted organs are shaded). (Reproduced with permission from [32].)

portal hypertension resulting in better utilization of nutrients. Further AGIR can also be performed post transplantation to reach enteral autonomy $[31,130,131]$. Despite the reported benefits, iLTx should not become the standard of care but should rather be considered with extreme caution in children with SBS and IFALD. Nutritional outcomes should be followed closely to determine the need for additional AGIR surgeries or intestinal transplantation in the long term.

\section{Conclusion}

Management of intestinal failure resulting from SBS continues to be a huge challenge. The potential benefits of both AGIR and intestinal transplantation in surgical management of short gut are now well evident. AGIR procedures offer less complicated and inexpensive techniques of achieving enteral autonomy using one's own bowel. Although intestinal transplantation has demonstrated a clear life-saving role in managing life-threatening intestinal failure, its benefits are limited by organ availability as well as significant financial and physical implications. However, best patient outcomes can be achieved through an individualized plan and a multidisciplinary approach with expertise available at an intestinal rehabilitation center.

\section{Disclosure Statement}

The author does not have any conflicts of interest regarding this article. 


\section{References}

1 Wilmore DW, Dudrick SJ: Growth and development of an infant receiving all nutrients exclusively by vein. JAMA 1968;203:860-864.

2 Modi, BP, Langer M, Ching YA, et al: Improved survival in a multidisciplinary short bowel syndrome program. J Pediatr Surg 2008;43:20-24.

$\checkmark 3$ Sigalet D, Boctor D, Brindle M, Lam V, Robertson M: Elements of successful intestinal rehabilitation. J Pediatr Surg 2011;46:150-156.

$\checkmark 4$ Sudan D, DiBaise J, Torres C, Thompson J, Raynor S, Gilroy R, Horslen S, Grant W, Botha J, Langnas A: A multidisciplinary approach to the treatment of intestinal failure. J Gastrointest Surg 2005;9:165-177.

5 Squires RH, Duggan C, Teitelbaum DH, et al: Natural history of pediatric intestinal failure: initial report from the Pediatric Intestinal Failure Consortium. J Pediatr 2012;161:723-728.e2.

6 Pironi L, Joly F, Forbes A, et al: Long-term followup of patients on home parenteral nutrition in Europe: implications for intestinal transplantation. Gut 2011;60:17-25.

7 Andorsky DJ, Lund DP, Lillehei CW, et al: Nutritional and other postoperative management of neonates with short bowel syndrome correlates with clinical outcomes. J Pediatr 2001;13:27-33.

$>$ Anagnostopoulos D, Valioulis J, Sfougaris D, et al: Morbidity and mortality of short bowel syndrome in infancy and childhood. Eur J Pediatr Surg 1991; 1:273-276.

$\checkmark 9$ Georgeson KE, Breaux CW Jr: Outcome and intestinal adaptation in neonatal short-bowel syndrome. J Pediatr Surg 1992;27:344-350.

10 Spencer AU, Kovacevich D, McKinney-Barnett M, et al: Pediatric short-bowel syndrome: the cost of comprehensive care. Am J Clin Nutr 2008;88:15521559.

11 Goulet O, Ruemmele F, Lacaille F, et al: Irreversible intestinal failure. J Pediatr Gastroenterol Nutr 2004:38:250-269.

12 Thompson JS, Quigley EM, Adrian TE: Factors affecting outcome following proximal and distal intestinal resection in the dog: an examination of the relative roles of mucosal adaptation, motility, luminal factors, and enteric peptides. Dig Dis Sci 1999; 44:63-74.

13 Schmidt T, Pfeiffer A, Hackelsberger N, Widmer R, Meisel C, Kaess H: Effect of intestinal resection on human small bowel motility. Gut 1996;38:859863.

14 Dowling RH: Intestinal adaptation. N Engl J Med 1973;288:520-521.

15 Wilmore DW, Byrne TA, Persinger RL: Short bowel syndrome: new therapeutic approaches. Curr Probl Surg 1997;34:389-444.

16 Weaver LT, Austin S, Cole TJ: Small intestinal length: a factor essential for gut adaptation. Gut 1991;32:1321-1323.

17 DiBaise JK, Young RJ, Vanderhoof JA: Intestinal rehabilitation and the short bowel syndrome: part 2. Am J Gastroenterol 2004;99:1823-1832.

18 Hofmann AF, Poley JR: Role of bile acid malabsorption in pathogenesis of diarrhea and steatorrhea in patients with ileal resection. I. Response to cholestyramine or replacement of dietary long chain triglyceride by medium chain triglyceride. Gastroenterology 1972;62:918-934.

19 Spencer AU, Neaga A, West B, et al: Pediatric short bowel syndrome: redefining predictors of success. Ann Surg 2005;242:403-409; discussion 409-412.
20 Struijs MC, Diamond IR, de Silva N, Wales PW: Establishing norms for intestinal length in children. J Pediatr Surg 2009;44:933-938.

21 Soden JS: Clinical assessment of the child with intestinal failure. Semin Pediatr Surg 2010;19:10-19.

22 Shiomi M, Wakabayashi Y, Sano T, Shinoda Y, Nimura Y, Ishimura Y, Suematsu M: Nitric oxide suppression reversibly attenuates mitochondrial dysfunction and cholestasis in endotoxemic rat liver. Hepatology 1998;27:108-115

23 Kaufman SS, Loseke CA, Lupo JV, Young RJ, Murray ND, Pinch LW, Vanderhoof JA: Influence of bacterial overgrowth and intestinal inflammation on duration of parenteral nutrition in children with short bowel syndrome. J Pediatr 1997;131:356-361.

24 Cole CR, Ziegler TR: Small bowel bacterial overgrowth: a negative factor in gut adaptation in pediatric SBS. Curr Gastroenterol Rep 2007;9:456-462

25 Thompson JS: Surgical considerations in the short bowel syndrome. Surg Gynecol Obstet 1993;176: 89-101.

26 Wales PW, De Silva N, Kim JH, et al: Neonatal short bowel syndrome: a cohort study. J Pediatr Surg 2005;40:755-762.

27 Thompson JS, Weseman R, Rochling FA, Mercer DF: Current management of the short bowel syndrome. Surg Clin North Am 2011;91:493-510.

28 Kimura K, Soper RT: A new bowel elongation technique for the short bowel syndrome using the isolated bowel segment Iowa models. J Pediatr Surg 1993;28:792-794.

29 Modi BP, Javid PJ, Jaksic T, et al: First report of the international serial transverse enteroplasty data registry: indications, efficacy, and complications. J Am Coll Surg 2007;204:365-371.

30 Barksdale EM, Stanford A: The surgical management of short bowel syndrome. Curr Gastroenterol Rep 2002;229-237.

31 Gupte GL, Beath SV, Kelly DA, et al: Current issues in the management of intestinal failure. Arch Dis Child 2006;91:259-264.

32 Abu-Elmagd KM: Intestinal transplantation for short bowel syndrome and gastrointestinal failure: current consensus, rewarding outcomes, and practical guidelines. Gastroenterology 2006;130(suppl 1): S132-S137.

33 Mazariegos GV, Superina R, Rudolph J, et al: Current status of pediatric intestinal failure, rehabilitation, and transplantation: summary of a colloquium. Transplantation 2011;92:1173-1180.

34 Jones BA, Hull MA, Kim HB: Autologous intestinal reconstruction surgery for intestinal failure management. Curr Opin Organ Transplant 2010;15:341-345.

35 Bianchi A: From the cradle to enteral autonomy: the role of autologous gastrointestinal reconstruction. Gastroenterology 2006;130:S138-146.

36 Reinshagen K, Kabs C, Wirth H, et al: Long-term outcome in patients with short bowel syndrome after longitudinal intestinal lengthening and tailoring. J Pediatr Gastroenterol Nutr 2008;47:573-578.

37 Sudan D, Thompson J, Botha J, et al: Comparison of intestinal lengthening procedures for patients with short bowel syndrome. Ann Surg 2007;246:593-604.

38 Goulet O, Baglin-Gobet S, Talbotec C, et al: Outcome and long-term growth after extensive small bowel resection in the neonatal period: a survey of 87 children. Eur J Pediatr Surg 2005;15:95-101.

39 Khalil BA, Ba'ath M, Aziz A, et al: Intestinal rehabilitation and bowel reconstructive surgery: improved outcomes in children with short bowel syndrome. J Pediatr Gastroenterol Nutr 2012;54:505509.
0 Thompson JS: Surgical approach to the short bowel syndrome: procedures to slow intestinal transit. Eur J Pediatr Surg 1999;9:263-266.

41 Nicoldani C: Die Idee einer Enteroplastik. Wiener Med Presse 1887;50. Abstract in Fortschritte Med 1888;6:275

42 Baldwin-Price HK, Copp D, Singleton AO Jr: Reversed intestinal segments in the management of anenteric malabsorption syndrome. Ann Surg 1965;161:225-230.

43 Hammer JM, Seay PH, Johnston RL, et al: Effect of antiperistaltic gut segments on intestinal emptying time. J Mich State Med Soc 1959;58:1289.

44 Singleton A, Rowe E: Peristalsis in reversed loops of bowel. Ann Surg 1954;139:853.

45 Panis Y, Messing B, Rivet P, et al: Segment reversal of the small bowel as an alternative to intestinal transplantation in patients with short bowel syndrome. Ann Surg 1997;225:401-407.

46 Pigot F, Messing B, Chaussade S, Pfeiffer A, Pouliquen X, Jian R: Severe short bowel syndrome with a surgically reversed small bowel segment. Dig Dis Sci 1990;35:137-144.

47 Layec S, Beyer L, Corcos O, Alves A, Dray X, Amiot A, Stefanescu C, Coffin B, Bretagnol F, Bouhnik Y, Messing B, Panis Y, Kapel N, Joly F: Increased intestinal absorption by segmental reversal of the small bowel in adult patients with short-bowel syndrome: a case-control study. Am J Clin Nutr 2013;97:100-108.

48 Beyer-Berjot L, Joly F, Maggiori L, Corcos O, Bouhnik Y, Bretagnol F, Panis Y: Segmental reversal of the small bowel can end permanent parenteral nutrition dependency. An experience of 38 adults with short bowel syndrome. Ann Surg 2012;256:739-745.

49 Barksdale EM, Stanford A: The surgical management of short bowel syndrome. Curr Gastroentero Rep 2002;4:229-237.

50 Wales PW, Jancelewicz T, Romao RL, Piper HG, de Silva NT, Avitzur Y: Delayed primary serial transverse enteroplasty as a novel management strategy for infants with congenital ultra-short bowel syndrome. J Pediatr Surg 2013;48:993-999.

51 Devesa JM, Botella-Carretero JI, López Hervás P, Rey A, Die J, Calero A: Ultrashort bowel syndrome: surgical management and long-term results of an exceptional case. J Pediatr Surg 2008;43:E5-E9.

52 Lloyd DA: Antiperistaltic colonic interposition following massive small bowel resection in rats. J Pediatr Surg 1981;16:64-69.

53 Glick PL, de Lorimier AA, Adzick NS, Harrison MR: Colon interposition: an adjuvant operation for short gut syndrome. J Pediatr Surg 1984;19:719725.

54 Debongnie JC, Phillips SF: Capacity of the human colon to absorb fluid. Gastroenterology 1978;74: 698-703.

55 Kono K, Sekikawa T, Iizuka H, Takahashi A, Amemiya H, Takehana T, Ooi A, Fujii H, Matsumoto Y: Interposed colon between remnants of the small intestine exhibits small bowel features in a patient with short bowel syndrome. Dig Surg 2001;18:237-241.

56 Taha MO, Ribeiro MA Jr, de Oliveira Gomes P, Montero Frasson E, Plapler H, Ferreira R, Lapa AJ, Soucar C: Evaluation of the longitudinal musculature of segments of the distal colon interposed following extended jejunum-ileum resection. Microsurgery 1999;19:306-310. 
57 Flach A, Bähr R, Nissen KH: Subtotal resection of the small intestine in newborn infants and infants. Results of an inquiry (article in German). Padiatr Padol Suppl 1975;3:33-40.

58 Howard ER, Othersen HB Jr: Proximal jejunoplasty in the treatment of jejunal atresia. J Pediatr Surg 1973;8:685-690.

59 De Lorimier AA, Harrison MR: Intestinal plication in the treatment of atresia. J Pediatr Surg 1983;18:734-737.

60 Bianchi A: Intestinal loop lengthening - a technique for increasing small intestinal length. J Pediatr Surg 1980;15:145-151.

61 Thompson JS, Vanderhoof JA, Antonson DL: Intestinal tapering and lengthening for short bowel syndrome. J Pediatr Gastroenterol Nutr 1985;4:495-497.

62 Bianchi A: Intestinal lengthening: an experimental and clinical review. J R Soc Med 1984;77(suppl 3): 35-41.

63 Chahine AA, Ricketts RR: A modification of the Bianchi intestinal lengthening procedure with a single anastomosis. J Pediatr Surg 1998;33:1292-1293.

64 Goulet O, Sauvat F: Short bowel syndrome and intestinal transplantation in children. Curr Opin Clin Nutr Metab Care 2006;9:304-313.

65 Thompson J, Sudan D: Intestinal lengthening for short bowel syndrome. Adv Surg 2008;42:49-61.

66 Kimura K, Soper RT: A new bowel elongation technique for the short-bowel syndrome using the isolated bowel segment Iowa models. J Pediatr Surg 1993;28:792-794.

67 Yamazato M, Kimura K, Yoshino H, et al: The isolated bowel segment (Iowa model II) created in functioning bowel. J Pediatr Surg 1991;26:780-783.

68 El-Murr M, Kimura K, Ellsberg D, et al: Motility of isolated bowel segment Iowa model III. Dig Dis Sci 1994;39:2619-2623.

69 Waag KL, Hosie S, Wessel L: What do children look like after longitudinal intestinal lengthening. Eur J Pediatr Surg 1999;9:260-262.

70 Thompson JS, Pinch LW, Young R, et al: Longterm outcome of intestinal lengthening. Transplant Proc 2000;32:1242-1243.

71 Hosie S, Loff S, Wirth H, et al: Experience of 49 longitudinal intestinal lengthening procedures for short bowel syndrome. Eur J Pediatr Surg 2006;16: 171-175.

72 Weber TR: Isoperistaltic bowel lengthening for short bowel syndrome in children. Am J Surg 1999; 178:600-604.

73 Fusaro F, Hermans D, Wanty C, et al: Post-serial transverse enteroplasty bowel redilatation treated by longitudinal intestinal lengthening and tailoring procedure. J Pediatr Surg 2012;47:e19-22.

74 Kim HB, Fauza D, Garza J, et al: Serial transverse enteroplasty (STEP): a novel bowel lengthening procedure. J Pediatr Surg 2003;38:425-429.

-75 Kim HB, Lee PW, Garza J, Duggan C, Fauza D, Jaksic T: Serial transverse enteroplasty for short bowel syndrome: a case report. J Pediatr Surg 2003; 38:881-885.

76 Ehrlich PF, Mychaliska GB, Teitelbaum DH: The 2 STEP: an approach to repeating a serial transverse enteroplasty. J Pediatr Surg 2007;42:819-822.

77 Andres AM, Thompson J, Grant W, Botha J, Sunderman B, Antonson D, Langnas A, Sudan D: Repeat surgical bowel lengthening with the STEP procedure. Transplantation 2008;85:1294-1299.

78 Cowles RA, Lobritto SJ, Stylianos S, Brodlie S, Smith LJ, Jan D: Serial transverse enteroplasty in a newborn patient. J Pediatr Gastroenterol Nutr 2007;45:257-260.
79 Wales PW, Dutta S: Serial transverse enteroplasty as primary therapy for neonates with proximal jejunal atresia. J Pediatr Surg 2005;40:E31-E34.

80 Modi BP, Langer M, Duggan C, et al: Serial transverse enteroplasty for management of refractory D-lactic acidosis in short-bowel syndrome. J Pediatr Gastroenterol Nutr 2006;43:395-397.

81 Craig RM, Ehrenpreis ED: D-xylose testing. J Clin Gastroenterol 1999;29:143-150.

82 Crenn P, Coudray-Lucas C, Thuillier F, et al: Postabsorptive plasma citrulline concentration is a marker of absorptive enterocyte mass and intestinal failure in humans. Gastroenterology 2000;119:1496-1505.

83 Chang RW, Javid PJ, Oh JT, et al: Serial transverse enteroplasty enhances intestinal function in a model of short bowel syndrome. Ann Surg 2006; 243:223-228.

84 Andres AM, Thompson J, Grant W, et al: Repeat surgical bowel lengthening with the STEP procedure. Transplantation 2008;85:1294-1299.

85 Miyasaka EA, Brown PI, Teitelbaum DH: Redilation of bowel after intestinal lengthening procedures - an indicator for poor outcome. J Pediatr Surg 2011;46:145-149.

86 Piper H, Modi BP, Kim HB, Fauza D, Glickman J, Jaksic T: The second STEP: the feasibility of repeat serial transverse enteroplasty. J Pediatr Surg 2006;41:1951-1956.

87 Morikawa N, Kuroda T, Kitano Y, Tanaka H, Takayasu H, Fujino A, Shibata Y, Tanemura H, Muto M, Honna T: Repeat STEP procedure to establish enteral nutrition in an infant with short bowel syndrome. Pediatr Surg Int 2009;25:10071011.

88 Sudan D, Thompson J, Botha J, Grant W, Antonson D, Raynor S, Langnas A: Comparison of intestinal lengthening procedures for patients with short bowel syndrome. Ann Surg 2007;246:593-604.

89 Bianchi A: Longitudinal intestinal lengthening and tailoring: results in 20 children. J R Soc Med 1997;90:429-432.

90 Georgeson K, Halpin D, Figueroa R, et al: Sequential intestinal lengthening procedures for refractory short bowel syndrome. J Pediatr Surg 1994;29:316-320.

91 Reinshagen K, Zahn K, von Buch C, et al: The impact of longitudinal intestinal lengthening and tailoring on liver function in short bowel syndrome. J Pediatr Surg 2008;18:249-253.

-92 Modi BP, Javid PJ, Jaksic T, et al: First report of the international serial transverse enteroplasty data registry: indications, efficacy, and complications. J Am Coll Surg 2007;204:365-371.

93 Lillehei RC, Goott B, Miller FA: The physiological response of the small bowel of the dog to ischemia including prolonged in vitro preservation of the bowel with successful replacement and survival. Ann Surg 1959;150:543-560.

-94 Alican F, Hardy JD, Cayirli M, et al: Intestinal transplantation: laboratory experience and report of a clinical case. Am J Surg 1971;121:150-159.

95 Lillehei RC, Idezuki Y, Feemster JA, et al: Transplantation of stomach, intestine, and pancreas: experimental and clinical observations. Surgery 1967;62:721-741.

96 Okumura M, Mester M: The coming of age of small bowel transplantation: a historical perspective. Transplant Proc 1992;24:1241-1242.

97 Starzl TE, Rowe MI, Todo S, et al: Transplantation of multiple abdominal viscera. JAMA 1989; 261:1449-1457.
98 Goulet O, Révillon Y, Canioni D, et al: Two and one-half-year follow-up after isolated cadaveric small bowel transplantation in an infant. Transplant Proc 1992;24:1224-1225.

99 Grant D, Wall W, Mimeault L, et al: Successful small-bowel/liver transplantation. Lancet 1990; 335:181-184.

100 Calne RY, Rolles K, White DJ, et al: Cyclosporin A initially as the only immunosuppressant in 34 recipients of cadaveric organs: 32 kidneys, 2 pancreases, and 2 livers. Lancet 1979;2:1033-1036.

101 Starzl TE, Todo S, Fung J, et al: FK 506 for human liver, kidney, and pancreas transplantation. Lancet 1989;2:1000-1004.

102 Todo S, Reyes J, Furukawa H, et al: Outcome and analysis of 71 clinical intestinal transplantation. Ann Surg 1995;222:270-282.

103 Centers for Medicare \& Medicaid Services: Medicare Coverage Policy Decisions: Intestinal and Multivisceral Transplantation. CAG-00036. October 4, 2000.

104 Vianna RM, Mangus RS, Tector AJ: Current status of small bowel and multivisceral transplantation. Adv Surg 2008;42:129-150.

105 Grant D, Abu-Elmagd K, Reyes J, et al: Report of the Intestine Transplant Registry: a new era has dawned. Ann Surg 2005;241:607-613.

106 Moon JI, Selvaggi G, Nishida S, et al: Intestinal transplantation for the treatment of neoplastic disease. J Surg Oncol 2005;92:284-291.

107 Nishida S, Hadjis NS, Levi DM, et al: Intestinal and multivisceral transplantation after abdominal trauma. J Trauma 2004;56:323-327.

108 Vianna R, Giovanardi RO, Fridell JA, Tector AJ: Multivisceral transplantation for diffuse portomesenteric thrombosis in a patient with life-threatening esophagogastroduodenal bleeding. Transplantation 2005;80:534-535.

109 Yerdel MA, Gunson B, Mirza D, et al: Portal vein thrombosis in adults undergoing liver transplantation: risk factors, screening, management, and outcome. Transplantation 2000;69:1873-1881.

110 Di Benedetto F, Lauro A, Masetti M, et al: Outcome of isolated small bowel transplantation in adults: experience from a single Italian center (article in Italian). Minerva Chir 2005;60:1-9.

111 Fryer JP: Intestinal transplantation: an update. Curr Opin Gastroenterol 2005;21:162-168.

112 Kato T, Gaynor JJ, Selvaggi G, et al: Intestinal transplantation in children: a summary of clinical outcomes and prognostic factors in 108 patients from a single center. J Gastrointest Surg 2005;9: 75-89; discussion 89.

113 Gupte GL, Beath SV: Update on intestinal rehabilitation after intestinal transplantation. Curr Opin Organ Transplant 2009;14:267-273.

114 Colomb V, Goulet O: Nutrition support after intestinal transplantation: how important is enteral feeding? Curr Opin Clin Nutr Metab Care 2009; 12:186-189.

115 Zonta S, Doni M, Alessiani M, et al: Elemental enteral nutrition preserves the mucosal barrier and improves the trophism of the villi after small bowel transplantation in piglets. Transplant Proc 2007:39:2024-2027.

116 Horlsen SP: Optimal management of the postintestinal transplant patient. Gastroenterology 2006;130:S163-S169. 
117 Smith JM, Skeans MA, Horslen SP, Edwards EB, Harper AM, Snyder JJ, Israni AK, Kasiske BL Organ Procurement and Transplantation Network (OPTN) and Scientific Registry of Transplant Recipients (SRTR). OPTN/SRTR 2012 Annual Data Report. Am J Transplant 2014;14 (suppl 1):97-111.

118 U.S. Department of Health \& Human Services: Organ Procurement and Transplantation Network: data. http://optn.transplant.hrsa.gov/data/.

119 U.S. Department of Health \& Human Services, HRSA: OPTN/SRTR 2011 Annual Report. 2011. http://srtr.transplant.hrsa.gov/annual_reports/2011/ pdf/04_intestine_12.pdf.

120 Intestinal Transplant Registry Data. www.intestinaltransplant.org/itr.

121 Kato T, Selvaggi G, Gaynor JJ, et al: Inclusion of donor colon and ileocecal valve in intestina transplantation. Transplantation 2008;86:293-297.

122 Matsumoto CA, Kaufman SS, Fishbein TM: Inclusion of the colon in intestinal transplantation. Curr Opin Organ Transplant 2011;16:312-315.
23 Kato T, Tzakis AG, Selvaggi G, et al: Transplantation of the spleen: effect of splenic allograft in human multivisceral transplantation. Ann Surg 2007;246:436-444; discussion 445-446.

124 Cipriani R, Contedini F, Santoli M, et al: Abdominal wall transplantation with microsurgical technique. Am J Transplant 2007;7:1304-1307.

125 Ravindra KV, Martin AE, Vikraman DS, et al: Use of vascularized posterior rectus sheath allograft in pediatric multivisceral transplantation report of two cases. Am J Transplant 2012;12: 2242-2246.

126 Gondolesi G, Selvaggi G, Tzakis A, et al: Use of the abdominal rectus fascia as a nonvascularized allograft for abdominal wall closure after liver, intestinal and multivisceral transplantation. Transplantation 2009;87:1884-1888.

127 Mangus RS, Kubal CA, Tector AJ, Fridell JA, Klingler K, Vianna RM: Closure of the abdominal wall with acellular allograft in intestinal transplantation. Am J Transplant 2012;12(suppl 4): S55-59.
128 Sheth J, Sharif K, Lloyd C, et al: Staged abdominal closure after small bowel or multivisceral transplantation. Pediatr Transplant 2012;16:36-40.

129 Dell-Olio D, Beath SV, de Ville de Goyet J, et al Isolated liver transplant in infants with short bowel syndrome: insights into outcomes and prognostic factors. J Pediatr Gastroenterol Nutr 2009;48:334-340.

130 Botha JF, Grant WJ, Torres C, et al: Isolated liver transplantation in infants with end-stage liver disease due to short bowel syndrome. Liver Transpl 2006;12:1062-1066.

131 Taha A, Sharif K, Johnson T, Clarke S, Murphy M, Gupte G: Long-term outcomes of isolated liver transplantation for short bowel syndrome and intestinal failure-associated liver disease. J Pediatr Gastroenterol Nutr 2012;54:547-551.

132 Frongia G, Kessler M, Weih S, et al: Comparison of LILT and STEP procedures in children with short bowel syndrome. A systematic review of the literature. J Pediatr Surg 2013;48:1794-1805. 